\section{C CHRONIC DISEASE AND WORK: CHALLENGES FOR THE AGEING WORKFORCE}

CRL Boot. VU University Medical Centre, Amsterdam, The Netherlands

\subsection{6/oemed-2018-ICOHabstracts. 1562}

The working population is ageing and is pushed to prolong work participation until a higher age. As the prevalence of chronic disease increases with age, the proportion of individuals with a chronic disease in the workforce increases as well. More than half of workers aged 55 years and up is having at least one chronic disease. However, policies aimed to enhance work participation focus on the general population of older workers without distinguishing those with and without chronic health problems. The aim of this presentation is to present challenges and opportunities to support workers with a chronic disease to remain active in the workforce until a higher age.

A recent review shows the importance of workplace factors for work participation of workers with chronic disease. Physical or psychosocial job demands, work organisation and support, and workplace beliefs and attitudes have been shown to be associated with work functioning. Previous studies have shown that there are many similarities between workers with different chronic diseases related to the role of workplace factors on work participation. Many interventions have been developed and evaluated focused on specific chronic disease, or on work disability in general. Evidence from randomised trials and other research designs has shown general support for job modification, coordination of return to work, and organisational support from supervisors or higher management. Work adjustments, formal or informal can be helpful for workers with chronic disease to optimise their work environment and functioning at work and reduce sick leave.

Awareness on workers with chronic disease, in particular older workers with chronic disease is increasing. Recent findings show the importance of focussing on the group of (older) workers with chronic disease as they represent a large and vulnerable group within the working population. Given the increasing societal pressure to prolong work participation, it should not be forgotten that the group of older workers is not homogeneous, but consists of workers with chronic disease that may have special needs. A healthy work environment is a continuous concern. Job loss has major consequences of the patient, as well as for society, so prevention of job loss is important and should start at an early stage, by preventing and reducing sick leave. Scientists, practitioners, as well as policy makers should take this into account.

\section{9d MENTAL HEALTH AND WORK DISABILITY PREVENTION}

${ }^{1} \mathrm{~K}$ Nieuwenhuijsen, ${ }^{2} \mathrm{C}$ Dewa. ${ }^{1}$ Academic Medical Centre, University of Amsterdam, Department: Coronel Institute of Occupational Health, Amsterdam Public Health Research Institute, The Netherlands; ' Department of Psychiatry and Behavioural Sciences, University of California, Davis, Sacramento, California

\subsection{6/oemed-2018-ICOHabstracts. 1563}

Common Mental Disorders (CMDs) have an extensive impact on the lives of those affected. Knowledge on how mental health problems and disorders affect workers has been accumulating over the last decade. Apart from absenteeism and long-term work disability, mental health problems affect the work functioning and productivity while present at work (presenteeism). The various stages of work disability in workers with CMDs, still at work, absent from work, and in the process of returning to work, pose different challenges to professionals and researchers alike.

This presentation will highlight:

i. emerging research methodologies in the field of work and mental health;

ii. evidence on the consequences of mental health problems for workers and employers; and

iii. evidence from evaluation studies of stay-at-work and return-to-work strategies for workers with mental health problems will be discussed.

\section{9e STAKEHOLDER PERSPECTIVES OF RETURN-TO-WORK SUCCESS}

${ }^{1} \mathrm{~K}$ Williams-Whitt, ${ }^{2} \mathrm{~K}$ Cullen, ${ }^{3} \mathrm{DP}$ Gross, ${ }^{4}$ I Steenstra, ${ }^{5}$ WS Shaw, ${ }^{5} \mathrm{~A}$ Young, ${ }^{6} \mathrm{~K}$ Nieuwenhuijsen. ${ }^{1}$ University of Lethbridge, Calgary, Canada; ${ }^{2}$ Institute for Work and Health, Toronto, Canada; ${ }^{3}$ University of Alberta, Edmonton, Canada; ${ }^{4}$ Ryerson University, Toronto, Canada; ${ }^{5}$ Liberty Mutual Research Institute for Safety, Hopkinton, USA; ${ }^{6}$ Coronel Institute of Occupational Health, Amsterdam, The Netherlands

\subsection{6/oemed-2018-ICOHabstracts. 1564}

Introduction While a large number of measures have been used to assess return-to-work (RTW) outcomes for injured workers, none are comprehensive and few have been consistently utilised, or psychometrically tested. Researchers have long recognised that there is no standard or universal RTW outcome measure, and that this is a significant problem for program and intervention comparison. Furthermore, it is unclear whether conceptions of success are different for physical and mental health conditions. The purpose of this study is to develop and test a return-to-work success scale focused on at work success, rather than preparation to return.

Methods Phase I involves collaborative generation of potential scale items and sorting the items into similar dimensions or categories using a focus group method. Phase II involves preliminary data collection and Q-sort analysis. Phase III involves initial psychometric evaluation of reliability and validity for the initial scale in workers with mental health conditions and physical work injuries.

Results The results of Phase I will be reported. Stakeholders including workers with physical and mental health conditions, employers, insurers and occupational health practitioners participate in focus groups to generate 'return-to-work' success items. Participants are asked to identify one thing that indicates that a worker with a physical health condition has successfully returned to work, and one thing that indicates a worker with a mental health condition has successfully returned to work. The items generated are collaboratively sorted and categorised through a consensus building process. Conclusion Scale development will support improvement in RTW practice by producing a reliable set of measures that can be used to assess interventions or stakeholder programs and processes. From a theoretical perspective, the RTWSS will improve research by providing a psychometrically sound tool to more thoroughly measure RTW outcomes. It will also facilitate knowledge synthesis in systematic reviews and meta-analysis because the outcomes are directly comparable. 


\section{8}

\section{A CBT INTERVENTION FOR LONG TERM SICKNESS ABSENCE}

Lorraine Begley, Thérèsse Hodgins, John Mc Dermott. Vhi Corporate Solutions, Dublin

\subsection{6/oemed-2018-ICOHabstracts. 1565}

Introduction The longer an individual is out of work the less likely that individual will ever return to work. Research has shown that, after six consecutive months of absence an individual has only a $50 \%$ chance of returning to work, this falls to $20 \%$ after 12 months' continuous absence and $10 \%$ after 24 months' continuous absence.

To evaluate if a cognitive behavioural intervention (CBT) impacts on an individual's decision to return to the workplace following a long term absence as measured by an individual's successful return to their previous work or a decision to seek alternative employment in a cohort of 27 individuals who are long term absent from work (8-57 months).

Methods We reviewed all cases referred, over a three year period (2014-2016), for a CBT intervention. (12-14 sessions over an average of a 6 month period).

Results $70 \%$ of a cohort of 27 individuals returned to their previous work or were in a position to seek alternative employment.

Discussion The findings suggest that a CBT intervention does support recovery and rehabilitation to work. Although the intervention involved a small cohort, the findings provide justification for continued investment and expansion of the current programme.

\section{INFLUENCE OF SIGNIFICANT OTHERS' PERCEPTIONS, BELIEFS, ATTITUDES AND BEHAVIOUR ON WORK OUTCOME OF INDIVIDUALS WITH CHRONIC DISEASES: A SYSTEMATIC REVIEW}

${ }^{1} \mathrm{NC}$ Snippen*, ${ }^{1} \mathrm{HJ}$ de Vries, ${ }^{2} \mathrm{SJ}$ van der Burg-Vermeulen, ${ }^{3} \mathrm{M}$ Hagedoorn, ${ }^{1} \mathrm{~S}$ Brouwer. ${ }^{1}$ Department of Health Sciences, Community and Occupational Medicine, University of Groningen, University Medical Centre Groningen, Groningen, The Netherlands; ${ }^{2}$ Coronel Institute of Occupational Health, Academic Medical Centre, University of Amsterdam, Amsterdam, The Netherlands; ${ }^{3}$ Department of Health Psychology, University of Groningen, University Medical Centre Groningen, Groningen, The Netherlands

\subsection{6/oemed-2018-ICOHabstracts. 1566}

Introduction It is recognised that significant others (SOs) may play an important role in recovery and return-to-work processes of individuals with chronic diseases. However, not much is known about how cognitive behavioural factors of SOs (spouse/partner, family member or friend) influence work outcome of their relative. This systematic review assesses the available evidence on perceptions, beliefs, attitudes and behaviours of SOs related to work outcomes of individuals with chronic diseases.

Methods Relevant articles were identified in PubMed, Embase, PsycINFO, SocINDEX and Web of Science. We included studies reporting on SO factors related to work outcomes (return to work, staying at work, job retention, and work functioning) in working populations with various chronic diseases. A quality assessment was performed, level of evidence was assessed for factors found in quantitative studies, and the evidence was thematically synthesised.

Result Out of 5168 articles, 18 studies were included (15 qualitative and 3 quantitative) of moderate to high quality. Studies were on cancer, chronic pain, brain injuries and mental health disorders. Results show that SOs with a positive and encouraging attitude concerning the disease and its consequences had a positive influence on work outcome of their relatives. Negative illness perceptions and attitudes regarding the disease and its consequences were negatively associated. Additionally, encouraging and motivating behaviour and practical help with activities had a positive association, whereas advising and exerting pressure not to work were negatively associated with work outcome.

Discussion Perceptions, beliefs, attitudes and behaviours of SOs may have a facilitating or obstructing influence on work outcome. Therefore, involving SOs in prevention and intervention strategies may facilitate a positive work outcome of individuals with chronic diseases. More quantitative research is needed to confirm these findings, as the evidence was mostly based on qualitative studies.

\section{REALIST REVIEW OF WORKPLACE INTERVENTION PROGRAMS FOR MUSCULOSKELETAL DISORDERS}

${ }^{1,2} \mathrm{M}$-J Durand* ${ }^{1,2} \mathrm{C}$ Sylvain, ${ }^{3} \mathrm{~J}$-B Fassier, ${ }^{4}$ WS Shaw, ${ }^{5} \mathrm{JR}$ Anema, ${ }^{1,2} \mathrm{D}$ Tremblay, ${ }^{6} \mathrm{P}$ Loisel, ${ }^{1,2} \mathrm{M}-\mathrm{C}$ Richard. ' Université de Sherbrooke, Longueuil, Canada; ${ }^{2}$ Centre de recherche deI'Hôpital Charles-Le Moyne, Longueuil, Canada; ${ }^{3}$ Hospices Civils de Lyon et Université Claude-Bernard-Lyon-1, Lyon, France; ${ }^{4}$ Liberty Mutual Research Institute for Safety, Boston, USA; ${ }^{5}$ VU University Medical Centre, Amsterdam, Netherlands; ${ }^{6}$ University of Toronto, Toronto, Canada

\subsection{6/oemed-2018-ICOHabstracts. 1567}

Introduction Musculoskeletal disorders (MSDs) are one of the main causes of work disability (TMS), yet some rehabilitation programs (RPs) effectively promote return to work. However, the level of implementation of these RPs remains low. Better understanding of what works in these programs is needed to improve implementation.

Objective Explain which contextual elements and components of these RPs work, for whom and in what circumstances.

Method A realist review of the literature was conducted using Pawson's approach (2006). Searches were performed in the Cochrane Work Trials Register, CENTRAL, MEDLINE, Embase and PsycINFO databases using pertinent keyword combinations. Each member of a group of experts $(n=4)$ analysed the articles independently and generated configurations (Context-Mechanism-Outcome). The configurations were compared and discussed to produce a final list by consensus. Demi-regularities (patterns) were sought in the configurations as a whole to discern groupings. A Web survey of potential users was conducted to assess the clarity, pertinence and exhaustiveness of the recommendations.

Results A total of 24 articles were retained and analysed. Around 50 configurations were developed and then grouped. Five RP components emerged:

- assessment of the individual, including the work situation;

- timeliness of the workplace intervention;

- diversity of stakeholders;

- intersectoral information-sharing, and

- workplace accommodations.

These RP components yield positive RTW outcomes for various types of workers (manual or sedentary), regardless of MSD site (back or upper limb) and MSD phase (acute, subacute or chronic). The results of the 31-user survey revealed that the recommendations were mostly deemed clear, pertinent and exhaustive. However, four were considered difficult to implement in workplaces. 